\title{
Policy responses to problematic video game use: A systematic review of current measures and future possibilities
}

\author{
ORSOLYA KIRÁLY ${ }^{1 *}$, MARK D. GRIFFITHS ${ }^{2}$, DANIEL L. KING ${ }^{3}$, HAE-KOOK LEE ${ }^{4}$, SEUNG-YUP LEE ${ }^{4}$, FANNI BÁNYAI ${ }^{1,5}$, \\ ÁGNES ZSILA ${ }^{1,5}$, ZSOFIA K. TAKACS ${ }^{6}$ and ZSOLT DEMETROVICS ${ }^{1}$ \\ ${ }^{1}$ Institute of Psychology, Eötvös Loránd University, Budapest, Hungary \\ ${ }^{2}$ International Gaming Research Unit, Nottingham Trent University, Nottingham, UK \\ ${ }^{3}$ School of Psychology, The University of Adelaide, Adelaide, SA, Australia \\ ${ }^{4}$ Uijeongbu St. Mary's Hospital, College of Medicine, The Catholic University of Korea, Seoul, Republic of Korea \\ ${ }^{5}$ Doctoral School of Psychology, Eötvös Loránd University, Budapest, Hungary \\ ${ }^{6}$ Institute of Education, Eötvös Loránd University, Budapest, Hungary
}

(Received: April 21, 2017; revised manuscript received: July 28, 2017; accepted: July 30, 2017)

\begin{abstract}
Background and aims: Empirical research into problematic video game playing suggests that overuse might cause functional and psychological impairments for a minority of gamers. Therefore, the need for regulation in the case of video games (whether governmental or self-imposed) has arisen but has only been implemented in a few countries around the world, and predominantly in Asia. This paper provides a systematic review of current and potential policies addressing problematic gaming. Methods: After conducting a systematic search in the areas of prevention, treatment, and policy measures relating to problematic Internet and video game use, papers were selected that targeted problematic gaming policies $(N=12$; six in English and six in Korean). These papers served as the basis of this review. Results: Policies were classified into three major groups: (i) policy measures limiting availability of video games (e.g., shutdown policy, fatigue system, and parental controls), (ii) measures aiming to reduce risk and harm (e.g., warning messages), and (iii) measures taken to provide help services for gamers. Beyond the attempt to classify the current and potential policy measures, the authors also tried to evaluate their efficiency theoretically and (if data were available) empirically. Discussion and conclusions: Overall, it appears that although several steps have been taken to address problematic video game playing, most of these steps were not as effective as expected, or had not been evaluated empirically for efficacy. The reason for this may lie in the fact that the policies outlined only addressed or influenced specific aspects of the problem instead of using a more integrative approach.
\end{abstract}

Keywords: problematic video game playing, Internet Gaming Disorder, gaming policy, gaming addiction regulation

\section{INTRODUCTION}

Recent technological development has seen video gaming become one of the most popular leisure time activities across both genders and all age groups (Entertainment Software Association, 2015). Unfortunately, similar to other highly rewarding activities, a minority of gamers pursue the activity in such an excessive manner that it leads to negative life consequences (i.e., impaired interpersonal relationships, decrease in work or educational performance, neglected personal hygiene and other needs, etc.) (Király, Nagygyörgy, Griffiths, \& Demetrovics, 2014; Männikkö, Billieux, \& Kääriäinen, 2015). Consequently, problematic gaming has come to the attention of clinicians and researchers in many countries around the world leading to a growing literature in the field and to its recent inclusion in Section III of the latest (fifth) edition of the Diagnostic and Statistical Manual of Mental Disorders (DSM-5; American Psychiatric Association, 2013) under the name of Internet Gaming Disorder (IGD). In this context, there is a growing recognition of the potential benefits to introducing and expanding international efforts to prevent the onset and progression of excessive gaming behaviors in vulnerable populations (for further insight, see King \& Delfabbro, 2017; King et al., 2017).

Section III of the DSM-5 (entitled "Emerging Measures and Models") comprises those mental problems that need further empirical evidence to be considered as mental disorders to be included in the main DSM text. The inclusion stirred a heated debate among scholars some of whom argued that it is too early to label this problem behavior a genuine addiction regardless of the shared similarities with substance use disorders or gambling disorder (see Griffiths et al., 2016; Király, Griffiths, \& Demetrovics, 2015). Apart from the definitional and conceptual debate, scholars tend to

\footnotetext{
* Corresponding author: Orsolya Király; Institute of Psychology, Eötvös Loránd University, Izabella utca 46, Budapest 1064, Hungary; Phone: +36 30514 7414; Fax: +36 1461 2697; E-mails: kiraly.orsolya@ppk.elte.hu; orsolya.papay@gmail.com
}

This is an open-access article distributed under the terms of the Creative Commons Attribution-NonCommercial 4.0 International License, which permits unrestricted use, distribution, and reproduction in any medium for non-commercial purposes, provided the original author and source are credited, a link to the CC License is provided, and changes - if any - are indicated. 
agree that problematic gaming exists in a sense that the aforementioned minority of gamers play so excessively that their life suffers detrimentally as a consequence (Griffiths et al., 2016; Király, Griffiths, et al., 2015).

Much of the literature deals with potential correlates or factors associated with problematic gaming. Although there is a lack of longitudinal studies (Scharkow, Festl, \& Quandt, 2014), it appears that the development of problematic video game use is a complex process comprising many different contributing factors (Kuss \& Griffiths, 2012). Despite the controversy of how problematic should be termed, many scholars have claimed that video gaming has a high addictive potential (e.g., King, Delfabbro, \& Griffiths, 2010, 2011). As the products of a profit-oriented industry, the objective of game developers and publishers is to create attractive and enjoyable games that are played by as many gamers as possible for as long as possible as this increases revenue streams for the gaming industry. To attain repetitive play, developers use game design elements based on psychological mechanisms [e.g., operant conditioning via variable-ratio reinforcement schedules (e.g., obtaining valuable in-game rewards at irregular and unpredictable intervals)] that promote player investment on a long-term basis (Charlton \& Danforth, 2007; King et al., 2010, 2011). Due to the immersive nature of video games, a large number of gamers play intensively (i.e., more than $20 \mathrm{hr}$ a week), although only a few of them suffer from negative consequences (Demetrovics et al., 2012; Pontes, Macur, \& Griffiths, 2016). The reason for this, as research suggests, may lie in the personal characteristics of gamers rather than those of the games alone. Psychiatric symptoms and distress, family background, motives to play (e.g., escapism), and a probable genetic predisposition might also have a role in whether gaming behavior becomes problematic or remains a harmless (or even beneficial) leisure time activity (Griffiths, Kuss, \& King, 2012; Király, Urbán, et al., 2015; Kuss \& Griffiths, 2012; Lee, Lee, \& Choo, 2017).

Given that problematic use of video games has been considered a growing public health issue, it raises the possibility of introducing or strengthening governmental regulation, similar to other addictive behaviors (e.g., alcohol consumption and gambling) that have been subject to regulation across numerous countries for some time (Humphreys \& McLellan, 2011). At present, policies regarding problematic gaming mostly exist in Asian countries such as the Republic of Korea (South Korea) and China.

The South Korean household subscription rate for highspeed Internet connection is the highest in the world (OECD, 2016) and Internet usage has continued to rise reaching $85.1 \%$ across all ages in 2015 (up from 83.6\% in the previous year) (Statistics Korea, 2016). In the Korean national representative survey of 18,500 participants in 2015, 6.8\% reported at least some problems related to excessive Internet use and $1.2 \%$ were considered to have a significant problem (Ministry of Science - ICT and Future Planning \& National Information Society Agency, 2015). Smartphone penetration rate in South Korea is also one of the highest in the world (YonhapNews, 2015). It was reported that $16.2 \%$ of Koreans displayed at least some problems related to smartphone and $2.4 \%$ showed highly problematic conditions that may require treatment (Ministry of Science - ICT and Future Planning \& National
Information Society Agency, 2015). With such an environment, the Internet gaming industry grew rapidly over the past few years in South Korea and in 2014, the Korean online and mobile game market respectively comprised for $19.1 \%$ and $14.3 \%$ in the global game market (Korea Creative Content Agency, 2015).

The widespread penetration of information technologies and highly developed online gaming industry has led to concerns related to problematic gaming with $13.8 \%$ being at risk of having IGD according to the DSM-5 criteria in an online survey having a convenience-based sample of 3,041 adults (Kim et al., 2016). The presumed high prevalence of gaming-related problems has led to the development of legislation and policies aimed at preventing and reducing negative consequences associated with excessive gaming. These policies (discussed below) involve regulation in regard to gaming content (i.e., rating systems) as well as regulation limiting the accessibility to gaming.

Video game-related regulations in the Western world are mainly limited to the rating systems evaluating content and age-appropriateness rather than overuse. More specifically, there is, for instance, the Pan European Game Information (PEGI) rating system operative in Europe or the one established by the Entertainment Software Rating Board (ESRB) used in North America. Both rating systems were respectively created by independent self-regulatory organizations representing the interactive software sector in Europe and the video game industry in the United States, to help consumers (mostly parents) make informed decisions on buying ageappropriate video games. Although both rating systems are primarily enforced on a voluntary basis rather than by federal or state laws, video game developers, publishers, and retailers tend to strongly adhere to them (Dogruel \& Joeckel, 2013). For instance, many American retailers refuse to sell video games without ESRB ratings which further enforces video game publishers to obtain ratings for their games.

In addition to game content (e.g., sex, violence, drug use, offensive language, etc.), empirical research into problematic gaming suggests that overuse is also a real issue. Therefore, the need for regulation (whether governmental or selfimposed) has arisen but has only been implemented in a few countries around the world, and predominantly in Asia. Consequently, this paper provides a systematic review of problematic video gaming policies, including possible further alternatives that might be implemented in the future. It also classifies these policy measures and evaluates their efficiency both theoretically and (if data were available) empirically.

\section{METHODS}

After conducting a systematic search in the areas of prevention, treatment, and policy measures relating to problematic Internet and video game use, papers were selected that targeted problematic gaming policies $(N=12)$. These papers served as the basis of this review. It is important to note that some of these papers use the term "problematic Internet use" (or "Internet addiction") rather than "problematic gaming," but indicated online gaming as the major concern within the context of problematic Internet use. This conflation of problematic gaming and Internet use is a 
widespread practice in the literature (e.g., Huang, Zhang, et al., 2010) and even in the DSM-5 itself (Griffiths et al., 2016), in spite of the fact that empirical research demonstrates that these two activities are separate nosological entities (Király, Griffiths, et al., 2014; Montag et al., 2015; Rehbein \& Mößle, 2013).

The systematic literature search involved the following databases: Web of Knowledge, Science Direct, PubMed, and Google Scholar, customizing the following search algorithm to the search engine of each database: "(video gam* or online gam* or internet gam* or computer gam* or internet or internet use) AND (addict* or problem* or pathological or excessive or compulsive or disorder* or dependen*) AND (treatment or prevention or intervention or policy or therapy) NOT (gambling or gambler or gamble)." Each search was performed in the title of the papers for the following reasons: (i) searching in the title was the only option available across all these search engines; (ii) it was assumed that searching in the title limited the number of appropriate papers to the most relevant ones; and (iii) by searching in the full text or topic of the papers the number of hits was unmanageably large. The two main inclusion criteria for the search were papers published (i) in peerreviewed journals and (ii) between 2000 and 2016. The latter criterion was chosen because most of the literature of these problem behaviors (i.e., problematic Internet and video game use) has been published since 2000. The search yielded a total of 1,858 hits: 379 on Web of Knowledge, 111 on Science Direct, 228 on PubMed, and 1,140 on Google Scholar. Given the large number of Google Scholar results, the first 35 pages (20 hits per page equaling 700 hits) were downloaded. After deleting duplicate hits, the remaining 1,099 results were scanned manually based on the title, abstract and, if necessary, the full text to identify the relevant hits and classify them according to their focus. In addition, during this manual selection, the reference lists of the relevant papers were also examined to identify further papers that were not found during the electronic database search. As a result of the systematic literature search, there were 124 treatment-related papers, 28 prevention-related papers, and (as mentioned earlier) 12 papers discussing policy-related matters and issues. Of these 12 papers, half were in English and half were in Korean. All 12 papers can be found in the reference list marked by an asterisk $\left(^{*}\right)$.

\section{RESULTS}

The authors aimed to list and classify all the possible policies and regulation measures that emerged in the literature as well as complementing these with hypothetical ones that logically arose from the existing ones. The main categories identified (i.e., limiting availability, reducing risk and harm, and proving help service for gamers) helped to group the measures and emphasized the most common factors behind them. Nevertheless, we acknowledge that some of the categories may overlap. Given the aim of this review, a more inclusive structure was applied. Instead of only listing and categorizing the findings in the "Results" section and adding the present authors' own hypothetical measures in the "Discussion" section, these have been integrated into the "Results" section to make the review more comprehensive and easier to follow. We have clearly indicated which measures are hypothetical only ("Potential measures") and which are currently in use or were applied in the recent past ("Current measures"). Furthermore, we have also indicated which measures are based on the present authors' own ideas and which measures were identified in the papers found so that the readers can easily differentiate between the two. Finally, some commentary is provided on individual measures in the "Results" section, while keeping the "Discussion" section for a general and comprehensive evaluation related to all the categories and measures listed.

The six policy-related papers written in Korean were thoroughly examined by two Korean authors of this paper. One paper contained empirical data (Shin \& Chae, 2015), whereas the rest of the papers were reviews on government policies (Cho \& Jin, 2015; Chon, 2009; Han \& Koh, 2012; Kim, 2010, 2014). The only empirical study surveyed teachers and counselors who worked on media-related addiction in schools. Shin and Chae (2015) used the Delphi method to assess which policies would be given a higher priority to help students with media-related addiction. Those deemed the best approaches comprised training programs delivering techniques on counseling, problem solving, and instructions for assessment tools concerning media-related addiction. However, the study's sample size was too small $(N=15)$ to draw far-reaching conclusions. The other five review papers mostly provided simple summaries on current government policies on Internet use and/or gaming with some suggestions of their own. Of these, only two papers were deemed worthwhile to be introduced in this paper (Kim, 2010, 2014).

These papers show that there are mainly two legislative directions driven by the Ministry of Gender Equality and Family (MGEF) and the Ministry of Culture, Sports and Tourism (MCST) in South Korea. Through juvenile protection, the MGEF advocates regulation on Internet gaming to protect youth. However, the MCST advocates that the shutdown policy (that prohibited late night gaming by young children to protect them from sleep deprivation) may impinge on the constitution that forbade overregulation and that gaming matters should be dealt with by the Game Industry Promotion Act. It was argued that it is not appropriate for the agency promoting the gaming industry to also be given the authority of regulating the industry. In addition, considering that Internet-related problems are a national matter, legislative directions should (i) not be limited to youth but should include all ages and not be confined to online gaming but should also deal with Internet addiction more generally; (ii) not only involve the central and local governments but also include the Internet service providers to engage in promoting systemic governance; (iii) make regulations reasonable by giving due consideration to other laws, individual rights, and development of technologies; (iv) impose more specific regulations on the Internet service providers as the current legislations lack detail and simply state that they should cooperate with government policies; and (v) introduce certified course for Internet addiction for counselors and establish regional Internet addiction centers (Kim, 2010). 
The other paper provided a more detailed review on Internet addiction prevention policies in South Korea, depending on the different values and policy objectives by each governmental department (Kim, 2014). The relevant ministries were evaluated as either aiming for (i) protection or (ii) gaming industry promotion. The departments seeking protection were the Ministry of Science, ICT and Future Planning (MSIP), the MGEF, the Ministry of Education, and the Ministry of Health and Welfare. The departments seeking the proliferation of the gaming industry were the MCST and Korea Communications Commission.

The stance taken by the MCST is that it does not accept the existence of "media addiction" and it views the problem as concerning "over-committed" users. Due to opposition from the MCST, the MEGF faced difficulties in the policymaking process of "shutdown legislation." This was viewed as a dilemma due to the conflict between two opposing values - "protecting youth from addiction" versus "promoting industrial development." Kim (2014) also divided the interest groups into (i) those in favor of Internet addiction prevention (parents, teachers, and non-governmental organizations) and (ii) those opposing regulation (companies related to Internet and gaming). This conflict of values has contributed to the dilemma in the policymaking. The author concluded that the South Korean government needed to establish a clear integrated policy goal to overcome such conflicts and overlapping roles.

In policymaking, the phenomenon of conflict was most noticeable in the area of "gaming," whereas the phenomenon of overlapping roles was most evident in the area of "youth." This may stem from the competitive efforts of policymakers to secure their own budgets. Initially, the South Korean government perceived the concept of "industry promotion" and "Internet addiction" as independent from each other. However, the South Korean government eventually realized these two areas were not independent of each other due to the growth of online industries and the advent of social problems related to Internet addiction (Kim, 2014). Consequently, the existing policies, developed in the period of not fully being aware of opposing conflicts, expanded independently under the separate policy goals of each government department and contributed to the current conflicting and overlapping roles. To overcome such challenges, prioritizing "protection" was viewed as the best way to solve the duplicating roles by recommending each department to attend to their core business sectors and gradually eliminate the overlapping areas (Kim, 2014). In the following section, current and potential (hypothetical) policy measures are listed and classified based mostly on the six policy-related papers written in English. For a summary of these policy measures, see also Table 1 .

\section{Limiting availability}

Given that the addictive potential of video games and increased gaming time are closely related with problematic use (e.g., Männikkö et al., 2015), one policy solution may be the limitation of gaming availability. If gamers are unable or less able to play video games excessively, there may be a reasonable chance to prevent the development of problematic use on a large scale. The measures listed below all attempt to prevent gamers from playing too much (regardless of how excessive use is defined), either by forced governmental regulation or by providing the people in charge (e.g., parents, other caregivers, or the gamers themselves) with appropriate tools to monitor and limit time spent on gaming.

Current measures to limit availability

Shutdown system. Here, governments oblige game service providers to block access to their online games between specific times in the day. For instance, in Thailand, the government implemented such measures in 2003, requiring all game servers (domestic and international) to be blocked between 10 p.m. and 6 a.m. (BBC News, 2003; Geek.com, 2003; Park \& Ahn, 2010). In the first action of its kind, the Thai government implemented such online game regulation in 2003, with a growing concern over a Korean role-playing game "Ragnarok Online" gaining a phenomenal popularity in Thailand (BBC News, 2003). The Thai government recommended that venues providing gaming access prohibit juvenile gaming from 10 p.m. until 6 a.m. However, the ban in Thailand was not implemented as a formal law and lasted for only 2 years until it was replaced with a juvenile non-access policy in Thai Internet cafés (Park, Ko, \& Park, 2013). A similar regulation was implemented in Vietnam in 2011 (Alexander, 2011), when the government asked Internet service providers to block access to all online games between 10 p.m. and 8 a.m.

Under Article 26 of the Juvenile Protection Act, the South Korean government (similar to the Thai government) also imposed regulation on the online game venue providers to reduce gaming access by teenagers under the age of 16 years of age from midnight to 6 a.m. Contravention of this law may result in up to 2 years of imprisonment or a fine of approximately $\$ 9,000$ (US). The South Korean shutdown system is viewed as one of the strongest regulations in attempts to inhibit problematic gaming. Since 2005, five attempts were made to pass the "shutdown" bill before it was introduced in April 2011. However, the shutdown laws faced strong opposition, particularly from the gaming industry. Prior its enactment in November 2011, the constitutionality of this new law was questioned in regard to the constitutional rights of freedom and equality for youth.

After two and half years, the constitutional court of South Korea finally judged that the shutdown law was constitutional. However, the ruling was criticized using the example of 2011 US Supreme Court which ruled that the Californian laws, which restricted sales and renting violent video games to minors, were unconstitutional (Park, 2012). After the introduction of shutdown policy, its effectiveness was evaluated by the MGEF of South Korea. According to the MGEF, the proportion of minors under the age of 16 years playing games after midnight decreased from $3.4 \%$ in 2011 to $0.9 \%$ in 2013 based on a nationwide survey of 10,062 students (National Youth Policy Institute, 2013). In addition, the socioeconomic benefit from shutdown policy was estimated to be as high as $\$ 453$ million (US) if $40 \%$ of problematic gamers under the age of 16 years stopped late night gaming in Korea (Lee, Kim, \& Lee, 2011).

In contrast, two studies reported that the shutdown system had no significant effects. However, the sample size in one study was very small $(n=273)$ (Sung, 2014). 
Policy responses to problematic video game use

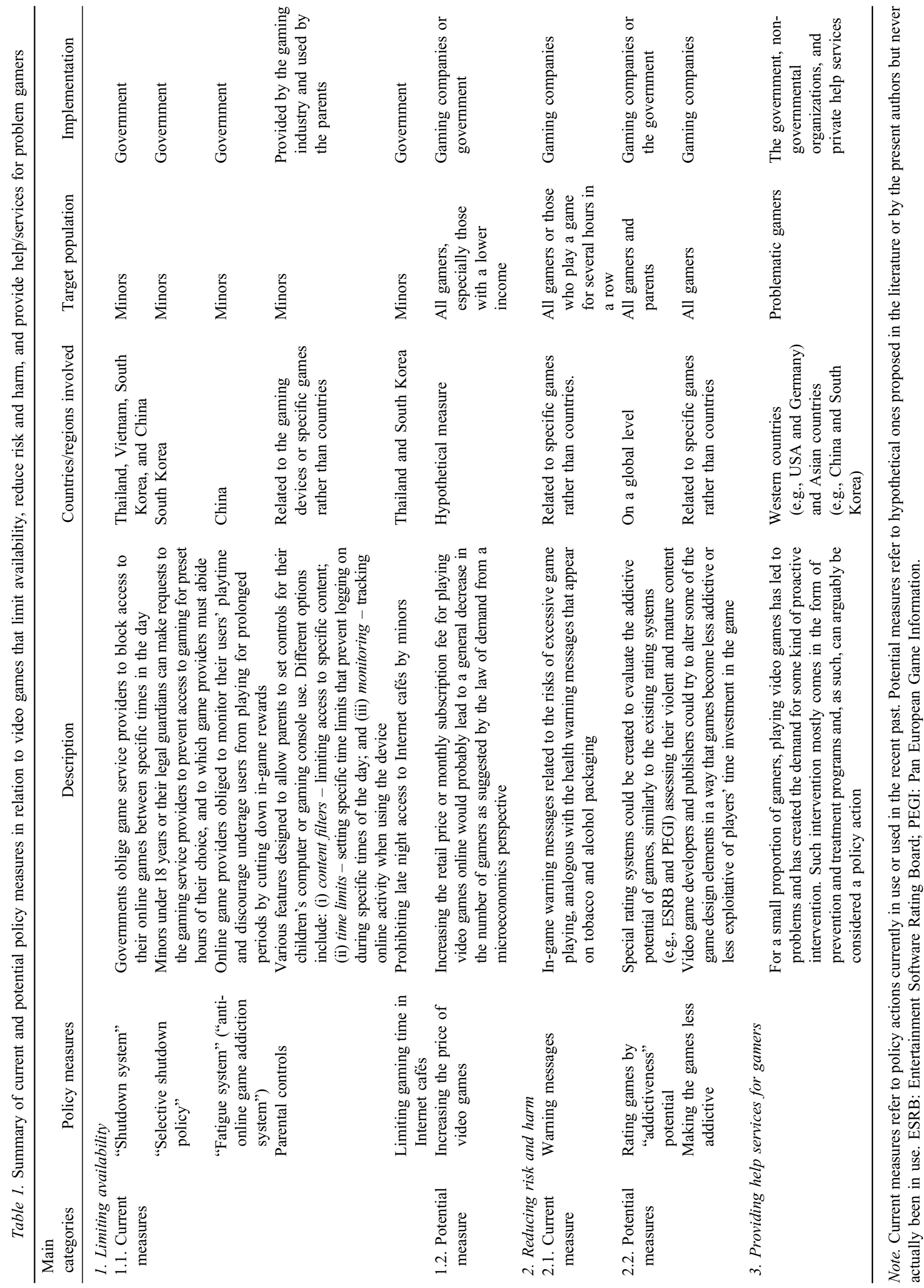


In another study, although the actual playing time decreased from 93.4 min (weekdays) and 157.3 min (weekend) per day (2010-2011; before the introduction of the shutdown law) to $85.9 \mathrm{~min}$ (weekdays) and $125.4 \mathrm{~min}$ (weekend) per day (2012-2013; after the introduction of the shutdown law), the effect was not statistically significant (Park et al., 2013). However, the analysis was done by the Korea Institute for Industrial Economics and Trade using survey data collected by the Korea Creative Content Agency, agencies that are both in the position of promoting the gaming industry. Even though the shutdown system faced strong opposition, this policy could be potentially more effective than other policies. For instance, it was reported that the impact of the shutdown regulation was greater than the impact of content regulation on the number of users (Hwang \& Park, 2015).

Davies and Blake (2016) designed an experiment to test the short-term effects of both the "shutdown" and the "fatigue" systems (see the latter below) among South African gamers playing a commercial single-player RPG game. They found that - if properly enforced - the "shutdown system" could indeed effectively control time spent gaming. However, it also had undesirable side effects. Namely, it significantly diminished the user experience, made gamers upset and unsatisfied, and as a result, they wanted to play more immediately after being forced to stop. The authors also emphasized that this measure is a "one-size-fits-all-gamesand-players solution" that fails to recognize both the structural properties of games and the individual differences between gamers (e.g., those being at risk of problematic gaming and those playing in a healthy manner). Consequently, they claim that such a policy may do more harm than good.

It should also be noted that China is also preparing for a similar shutdown policy. It was reported that the Cyberspace Administration of China is preparing a bill stricter than that in South Korea, banning game access to those under the age of 18 years of age from midnight to 8 a.m. (Li \& Zhou, 2016). Not only have the age and hours of restriction been increased but the Chinese government also plans to limit mobile gaming by requiring smartphone companies to preinstall regulatory software prior to selling (Seo, 2017).

Selective Shutdown Policy. In South Korea, a regulation called the "Selective Shutdown Policy" was introduced in the Game Industry Promotion Act $\S 12.3$ to limit the access of minors to online gaming upon request (Game Industry Promotion Act § 12.3; World Health Organization, 2014). This policy is equivalent to casino self-exclusion in that minors under the age of 18 years or their legal guardians can make requests to the gaming service providers to prevent access to gaming for preset hours of their choice, and to which game providers must abide. The first move for such legislation was initiated in 2006 and the bill was finally passed in 2011 (after four attempts) after stronger legislation of the non-selective "shutdown policy" was passed by the national assembly. Although this "Selective Shutdown Policy" is rarely used, the gaming industry advocates the abolition of the "shutdown policy" given that there is alternative regulation in the form of the "Selective Shutdown Policy."

Fatigue system (anti-online game addiction system). In 2007, China implemented a regulation, where online game providers were obliged to monitor their users' playtime and discourage underage users from playing for prolonged periods. Gamers had to register to online games with their real names and identification (ID) card numbers. After $3 \mathrm{hr}$ of gameplay, minors only got half of the experience points (XPs; points needed to advance in the game), whereas after $5 \mathrm{hr}$ of gameplay, XPs were reduced to zero. In addition, after $5 \mathrm{hr}$ of gameplay a message appeared in every $15 \mathrm{~min}$, warning players that they had entered unhealthy game time and should stop immediately (China Daily, 2007).

Opinions about the effectiveness of this policy have been varied. One newspaper article claimed that the anti-online game addiction system proved effective according to a nationwide survey by the China Youth Social Service Center because the number of underage players dropped by $7 \%$ in a 1 -year period $(\mathrm{Bi}, 2009)$. However, other sources draw attention to all the practical problems concerning the implementation of the regulation. For instance, lots of minors used the ID cards of their parents to register on the gaming platform and this was overlooked by Internet café owners to preserve their customers and income (Lan, 2010; Zhan \& Chan, 2012). Another major problem regarding this policy measure concerns the protection of private data. More specifically, if game companies are obliged to keep personal information on their servers against their will, there was uncertainty about who is responsible for the confidentiality of the data gathered in case of a hacker attack (Lan, 2010).

Another concern regarding these policies is the fear expressed by game companies of a potential loss of revenue. To address this concern, Park and Ahn (2010) ran a simulation of the implementation of these policy methods in the South Korean online gaming industry for a period from 2003 to 2020 . In the analysis, they tested the implementation of two policies: (i) a self-regulation policy in which the government allowed online game companies to adopt a fatigue system voluntarily, and (ii) a tax and rebate policy in which the government imposed a tax on every game company based on the number of active players and then offered a rebate for the gaming companies that adopted the fatigue system. According to their results, the total revenue of gaming companies increased in both cases along with a decline in the number of addicted game users and an improvement in the social image of online games. Furthermore, implementing the fatigue system with the tax and rebate policy appeared to be a better solution than the selfregulation policy. Nevertheless, it is important to keep in mind that this was a simulation and as such, it needed to simplify reality in a way that might have also impacted the conclusions. For instance, addicted gamers were defined as those "who play games seriously for extended periods of time" (Park \& Ahn, 2010, p. 123) regardless of how this affected their lives. Consequently, the number of truly problematic gamers may be far fewer than the number assumed in the simulation. Furthermore, decreasing the number of problematic gamers may also be much more difficult than simply reducing the number of those gamers who played for extended periods.

In the aforementioned experiment, Davies and Blake (2016) also tested the effects of the "fatigue system." As opposed to the shutdown system, the fatigue system did not have detrimental effects over the user experience. However, 
instead of decreasing the time spent playing video games, it increased it in the short-term. Nevertheless, this effect might have been caused by the experiment's limitations. Players were experiencing the "fatigue system" only once in the experiment with a new game they were unfamiliar with. Therefore, the novelty of the game might have made them want to play more even with getting less or no XPs (i.e., experience points). It is likely that if they had played the video game for a longer time and had experienced the "fatigue system" regularly, they would have been discouraged. Another important point raised by Davies and Blake (2016) is that the "fatigue system" should not only be based on stopping after a specific time period (e.g., playing the game for $3 \mathrm{hr}$ ) but should also take into consideration the possible exit points in the game. More specifically, the measure could take effect when gamers already playing for a longer time are close to a suitable exit point (e.g., the end of an in-game match).

Parental controls. Various features are designed to allow parents to set controls for their children's computer or gaming console use. Parental controls comprise several different options including: (i) content filters - limiting access to specific content, such as age-inappropriate content [e.g., games having $\mathrm{M}$ (Mature) or AO (Adult Only) ESRB ratings] or specific websites, applications or software; (ii) time limits setting specific time limits that prevent logging on during specific times of the day (e.g., after 8 p.m.); and (iii) monitoring - tracking online activity when using the device. Parental control features are available on most video game platforms (e.g., PlayStation, Xbox, and Wii) and operating systems (e.g., Windows, Mac, Android, and iOS).

Some gaming companies also offer their own parental control features. For instance, Blizzard Entertainment offers parental controls for all of its games stating: "We believe that real-world priorities such as homework, chores, and family dinner should take precedence over entertainment. Our Parental Controls provide parents and guardians with easy-to-use tools to set up rules for play time and manage access to Blizzard Entertainment games in a way that fits your family's situation" (Blizzard Entertainment Inc., 2016). The company offers the option of limiting children's play time ("All things in moderation, even Blizzard games! Using our parental controls, you can easily set daily or weekly limits on the hours your child is allowed to play our games"), the option to create specific gaming schedules for children ("In addition to specifying the maximum hours your child can play our games, you can create a custom play schedule. A selection of pre-set schedules such as 'after school \& weekends' and 'weekends only' is also available"), and several other options such as an option to receive reports on the amount of time spent playing and reports showing how much has been spent on in-game purchases.

The use of parental controls is largely up to the parents or guardians themselves. Government regulation could influence the availability of such controls (by forcing providers to implement these in all their gaming products) and statefinanced campaigns could raise awareness among parents regarding the usefulness of such features. However, there is no evidence on the efficacy of such measures in helping keep gaming behavior within limits and under control.
Limiting gaming time in Internet cafés. Such a measure was first used in Thailand where it was introduced in 2005 (Park et al., 2013). Here, young children can only play games online in Internet cafés between 2 p.m. and 8 p.m. during the school term and from 10 a.m. to 8 p.m. during holidays. Teenagers can play up to 10 p.m. on school days and during holidays. This is a government regulation and is strictly enforced. To protect children in South Korea, the government introduced a regulation in 2007 to prohibit late night access to Internet cafés by minors in Article 16 of the Game Industry Promotion Act Enforcement Ordinance. Unless accompanied by a legal guardian, providing services to minors under the age of 18 years outside the legally permitted hours (from 9 a.m. to 10 p.m.) result in the providers being financially penalized [i.e., about $\$ 900$ (US) for a first time offense with penalties doubling for subsequent offenses and suspension of service after three violations]. This policy is similar to regulations preventing alcohol and tobacco sales to minors through verifying their age in the sales points. In Internet cafés, the players can be asked to present their ID cards for age verification, and Internet cafés are monitored by the local authorities and fined if not abiding to the regulation. The drawback of such a regulation is similar to the difficulties experienced in the case of alcohol and tobacco regulations. Namely, that the profit-related interests of providers (Internet cafés in this case) would be in opposition to the health-related interests of the policymakers. As far as the authors are aware, the efficacy of this policy has not been formally evaluated.

Potential measures to limit availability

Increasing the price of video games. This measure is a hypothetical one as the present authors know of no jurisdiction that has implemented such a policy. However, increasing the retail price or monthly subscription fee for playing video games online would probably lead to a general decrease in the number of gamers as suggested by the law of demand from a microeconomics perspective. This could either be initiated by the gaming companies themselves, or be legislated for by the authorities through imposing higher taxes upon video games in general or specific games [e.g., those shown empirically to have a higher addictive potential such as MMORPGs (Eichenbaum, Kattner, Bradford, Gentile, \& Green, 2015; Elliott, Golub, Ream, \& Dunlap, 2012)]. Monies raised from such an initiative could be used to address public health issues related to gaming excess.

Similar to some of the aforementioned policies, increasing the price of video games or subscriptions to play would also have its difficulties in implementation. First, increasing the price of video games and potentially losing a significant percentage of their players would most probably also decrease the profits of gaming companies that would therefore not want to implement such a measure. Second, several video games exist at the moment that are completely free to play, and obtain revenue via in-game advertising or in-game purchases (i.e., micro-transactions, a business model where users can purchase virtual goods via micropayments). In the case of such games, changing the "freeto-play" business model might be one solution. However, this would involve an enormous structural change affecting a large sector of the video game industry (and may be contrary to the laws of a free market economy) and as such, 
it would arguably be difficult to implement. Furthermore, several games have free-to-play pirate versions hacked by gamers who possess good programming skills, and these illegal alternative versions are also difficult to regulate or control. [One possible way to control the availability of these pirate versions may be through the regulation of illegal downloading and uploading (e.g., via torrent or file sharing applications) - an existing practice in several countries (e.g., Germany)].

\section{Reducing risk and harm}

When talking about substance use, harm reduction refers to policies, programs, and/or practices that aim to reduce the adverse consequences associated with the use of psychoactive substances without necessarily reducing the degree of substance use itself (Marlatt, 1996). In parallel with this, the present authors argue that specific actions and strategies in the case of video games could also be viewed as risk and harm reduction tools. Contrary to the solutions listed in the previous section, these do not aim to limit availability in a forced way but either encourage and help gamers to play more responsibly, or intend to make the playing activity itself less hazardous.

Current measures in reducing risk of problematic gaming Warning messages. Some gaming companies post in-game warning messages related to the risks of excessive game playing. For instance, there are numerous loading screen tips in World of Warcraft of which two specifically address this issue: "Remember to take all things in moderation (even World of Warcraft!)" and "Bring your friends to Azeroth, but don't forget to go outside Azeroth with them as well." These messages are arguably analogous with the health warning messages that appear on tobacco and alcohol packaging (van Rooij, Meerkerk, Schoenmakers, Griffiths, \& van de Mheen, 2010), although they are voluntary initiatives devised by the gaming companies rather than ones used because there is a legal imperative. Nevertheless, their voluntary nature suggests that game developers are aware that some players will play their games in an excessive manner that may impact their lives negatively, even if they refuse to admit this publicly (Yousafzai, Hussain, \& Griffiths, 2014). Based on the efficiency of cigarette warning labels (Azagba \& Sharaf, 2013; Hammond, Fong, McDonald, Brown, \& Cameron, 2004), it may be assumed that such warning messages could be useful in raising awareness related to the possible detrimental consequences of excessive gaming.

However, when and for whom should such warnings be posted? In the aforementioned example, these two messages appear rarely and randomly (since they are part of a long list of loading screen tips that are randomized), whereas in other cases similar warning messages may appear every time when gamers log into the game (e.g., Final Fantasy XI). It is the present authors' opinion that a good solution might be to customize such warnings based on the amount of time each player spends in-game, sparing those gamers who play moderately, and specifically targeting those gamers who spend extreme amounts of time playing. For instance, those spending more than $25 \mathrm{hr}$ a week gaming could perhaps receive such messages.
Another type of warning message could also be used for those gamers who play a game for several hours in a row. Such players could be advised to take a break after a predetermined time (e.g., $3 \mathrm{hr}$ ). Several companies have already used such messages (e.g., Blizzard Entertainment, ArenaNet, and Nintendo). Such warning messages could be used by any gaming company, and based on the success of similar measures such as the ReThink anti-bullying software (Prabhu, 2014) or the use of such messages in gambling (Auer \& Griffiths, 2015; Auer, Malischnig, \& Griffiths, 2014), it is assumed that some players would appreciate and take advantage of it (as demonstrated in the gambling field), while the measure would be unlikely to seriously hurt the profitability of gaming companies. Furthermore, it would be a good public relations (PR) tool as it would give the impression they care about their players and their health.

Potential measures in reducing risk of problematic gaming Rating games by "addictiveness" potential. It has been asserted that existing rating systems (e.g., ESRB and PEGI) could be extended (van Rooij et al., 2010) and/or special rating systems could be created to evaluate the addictive potential of games as well as assessing their violent and mature content. Similar to the labels used in the ESRB system (e.g., C, E, T, M, AO; Entertainment Software Rating Board, 2016), risk categories could perhaps be developed depicting the addictive potential of the most popular games. Such attempts can already be seen in the case of gambling products in Germany (Peren, 2011) and in Hungary (Tessényi \& Peren, 2015), and many socially responsible gambling companies around the world use licensed software (e.g., GAM-GaRD and Asterig) to assess the riskiness of their gambling products before releasing them on the market (Griffiths, 2012).

Although in principle such a proposal would certainly help to raise awareness among gamers and their families regarding the possible dangers of overuse, the present authors note that assessing a video game's addictive potential is much more difficult than rating its' content. While violent and mature game elements can be quantified relatively easily, the addictive potential is a more abstract attribute. However, the structural characteristics of games (which are to some extent quantifiable) are necessary (but not sufficient) ingredients of a video game's addictive potential. If they were, game developers would have a much simpler task, namely, to combine as many addictive game elements as possible. Finding an ideal combination and/or introducing non-quantifiable additional characteristics (or just introducing an element by chance) can also make differences that would not necessarily be caught by risk assessment software. Therefore, simply quantifying the addictive game elements may not be a consistently reliable solution for rating the addictive potential of games. It is also the present authors' opinion that as an alternative solution, gaming reviews could be used. Games are subject to professional reviews, meaning that video game journalists that review games for gaming magazines (e.g., GameSpot, Giant Bomb, IGN, and GamesRadar) rate the games very seriously and can sometimes influence the sales of such games. In addition, each game has a so-called "metacritic score" (summarizing a large number of reviews from different online gaming magazines) that largely reflects the 
general success (and usually closely related to this: the addictive potential) of the video game in question. Consequently, this metacritic score combined with the evaluation of structural game elements could perhaps be used to help evaluate the addictive potential of video games.

Making the games less addictive. In an editorial about the social responsibility of the video game industry, Yousafzai et al. (2014) argued that video game developers and publishers could perhaps try to alter some of the game design elements in a way that games become less addictive, or less exploitative of players' time investment in the game. For instance, long quests could be shortened, the amount of experience points necessary for reaching the next level could be lowered, chances to get the desired items could be increased, etc. Overall, such modifications would make rewards easier to achieve and decrease the amount of time needed to advance in the game. Another approach suggested by the present authors - that would not involve compromising the reward system may be to offer greater transparency on the typical time required to complete in-game actions (similar to a film's running time in minutes) so that players feel better informed about their choices in the game.

However, changing these elements might lead to the games being less attractive, less enjoyable, less surprising, and ultimately less profitable. Consequently, it is unlikely that gaming companies would realistically consider such measures. In addition, the genres, designs, and/or other game-related elements that contribute to habitual gaming may differ by the gamers' individual needs and/or vulnerabilities (Lee et al., 2017). Thus, elimination of the addictive potential that corresponds to every gamer would be hard to achieve in practice. However, in South Korea, a bill has been proposed to oblige the game providers to disclose the probabilities of acquiring the "random items" in-game. A lawsuit was filed by two gamers against game providers to disclose the actual probabilities for acquiring items. The gamers had spent approximately $\$ 10,000$ (US) but failed to acquire their desired game items. However, the gamers lost their case in a regional court (thel.mt.co.kr, 2016). In Japan, there is gaming industry self-regulation that limits the expected cost of acquisition for a rare item to be less than $\$ 500$ (US), or to disclose the probability when the expected cost exceeds \$500 (US) (thisisgame.com, 2015).

There is great competition in the video game industry, and as already mentioned, games are subject to professional reviews that may directly influence the amount of sales. For this reason, each game developer attempts to develop the perfect game to get the best reviews possible. It also appears, that the so-called addictive potential of games often corresponds to those features that bring good reviews to the games. (Note that the term "addictive" is often used as the most positive attribute to describe a game; for instance see the following article "10 of the Most Addictive Video Games Ever Made"; Rawes, 2016.) Therefore, expecting gaming companies to decrease the addictive potential of their games appears to be an unrealistic expectation.

\section{Providing help services for gamers}

For a small proportion of gamers, the playing of video games has led to problems and has created the demand for some kind of proactive intervention. Such intervention mostly comes in the form of prevention and treatment programs and as such, can arguably be included within a list of policy actions. While a review of all the types of treatment for problematic gaming is beyond the scope of this paper, an important question from a policy point of view is who should provide such treatment services.

In the case of problematic video gaming, clinicians in private practice or private hospitals were among the first to recognize the need and the financial potential related to online problematic gaming behavior and offered some kind of help and/or treatment. For instance, in the United States several treatment centers and programs have been established, mostly by profit-oriented private organizations (e.g., The Center for Internet Addiction: http://netaddiction. com/). The most frequent therapeutic approach in these treatment programs is cognitive-behavioral therapy (King \& Delfabbro, 2014) but programs using combined therapy (e.g., pharmacotherapy, family therapy, and wilderness therapy) are also popular (Kuss \& Lopez-Fernandez, 2016).

Alternatively, offering prevention and treatment can be part of a national policy to combat problematic video game use. In China and South Korea, problematic Internet use and video gaming are considered serious public health issues (Stone, 2009). For this reason, entire national strategies have been developed to help deal with the problem. South Korea was the first country to allocate a national budget to deal with these problems of Internet and gaming addiction (Koh, 2015). As part of a national policy addressing this public health concern several ministries (i.e., MGEF, MCST, Ministry of Health and Welfare, Ministry of Education, Ministry of National Defense, Ministry of Justice, and the Korea Communications Commission) are involved in tackling the problem. In addition, there are also autonomous regional organizations (also state institutions) such as the Internet Addiction Prevention and Counseling Center (IAPC) that engage in systematic activity related to problematic Internet and gaming use (Koh, 2015). Similarly, China runs state-owned treatment centers such as the General Hospital of Beijing Military Region's Internet Addiction Treatment Center (Huang, Li, \& Tao, 2010; Stone, 2009) to address problematic gaming.

Internet gaming-related problems have often been reported in South East Asian countries, and intervention policies and treatment programs related to such problems have therefore been suggested and established in this region (Lee, 2015). Government-driven policies and intervention service systems have been conducted in South Korea since 2010. In response to the growing problem of Internet addiction, the South Korean government established the Internet Addiction Prevention \& Resolution Comprehensive Plan (in 2010), led by the National Safety Administrationaffiliated agency of the MSIP under the National Informatization Act and Game Industry Promotion Act. These plans focused on establishing the intervention system for problematic Internet use and problematic online game use.

The MSIP established 12 regional counseling service centers (Internet Addiction Prevention Center') and has been providing preventive education and counseling services. The MGEF has been conducting a screening and referral service among the entire 4th-, 7th-, and 10th-grade 
students in collaboration with the Ministry of Education. The MCST has been operating five "Game Overcommitment Healing Centers" via the Game Culture Foundation. In addition, the Ministry of Health and Welfare provides Internet addiction-related services via the community-based Addiction Management Centers, which previously focused mostly on providing services for those with alcohol problems, and began to expand their services to include behavioral addictions (such as online gaming addiction) in 2014. Arguably, these approaches can be recognized as a unique governmentguided integrative intervention system. However, they are also criticized for the lack of inter-agencies collaboration and clinical conceptualization in providing such services.

In Germany and other European countries, it is predominantly the addiction help system that provides prevention, counseling, and treatment for problematic Internet and gaming use (Dau, Hoffmann, \& Banger, 2015). For instance, the Addiction Division of Geneva University Hospital opened an outpatient clinic dedicated to the treatment of behavioral addictions (Thorens et al., 2014). In Germany, there are inpatient rehabilitation centers of the "German Federal Association of Inpatient Addiction Rehabilitation" (Müller et al., 2013) and an Outpatient Clinic for Behavioral Addictions that belongs to the University Medical Center Mainz (Wölfling, Beutel, Dreier, \& Müller, 2014).

In addition to state-financed treatment centers, there are similar facilities and programs run by non-governmental organizations. For instance, the Broadway Lodge treatment center in Somerset (United Kingdom) is a non-profit organization treating patients with all kinds of addictions including gambling, Internet use, and gaming (see https://broadwaylodge.org.uk/). Moreover, NGOs are appropriate organizational forms to establish self-help group therapy programs where patients and their families help each other, similar to self-help groups for patients with substance use disorders.

Finally, offering (or referring to) prevention and treatment programs can also be part of gaming companies' corporate social responsibility (CSR) measures. CSR refers to the "context-specific organizational actions and policies that take into account stakeholders' expectations and the triple bottom line of economic, social, and environmental performance" (Aguinis, 2011). In other words, businesses assume responsibility through these CSR actions and policies for the community they belong to (beyond maximizing their own financial profit). In the case of video gaming, CSR policies refer to those measures that help prevent or treat problematic use and are initiated by members of the gaming industry rather than official authorities or from those within the game playing community.

From a PR perspective, gaming companies are better served by having a large player base of healthy gamers than having a large number of problematic gamers who reflect discredit on the company and the industry as a whole, and it is arguably in their best interest to offer help for gamers and their families if they need it. Van Rooij et al. (2010) suggested that game developer companies could provide gamers with referral services, and that this could be part of their CSR portfolio. Since most gaming operators collect player data regarding time spent in-game, out of a "duty of care" they could contact those gamers who play much more time than the average and offer them contact information for possible referral services such as treatment centers, online self-help groups, and/or clinicians in private practice (depending on the local possibilities) as happens with gambling companies that use player tracking data (Auer \& Griffiths, 2015; Griffiths, 2012). Such a measure would not affect the profitability of the company negatively. In fact, such a measure would likely be considered as an appropriate CSR measure by critics, gamers, and gamers' families.

\section{Who should initiate and/or implement policy actions?}

The previous section briefly discussed who could (and should) be involved in prevention and treatment services concerning problematic gaming. In this section, the measures belonging to the first two categories (i.e., limiting availability and risk and harm reduction) are discussed in relation to who should initiate and/or implement such policy actions.

On the one hand, the "shutdown system," the "fatigue system," limiting gaming time in Internet cafés (if applicable), increasing the price of video games by imposing higher taxes, developing a rating system to evaluate the addictive potential of games, forcing gaming companies to include parental controls, and warning messages into their games or develop less addictive games could - at least theoretically be all imposed by national authorities. Nevertheless, it is important to point out that this largely depends on the political system in a given country. While in Asian countries where government control is strong, many of these actions could be implemented, in the Western world, most of these policy actions would perhaps be highly criticized and protested against as being an attack on civil liberty. Furthermore, there is a lack of robust evidence that such measures would be successful in reducing the number of problematic gamers.

On the other hand, all these measures (except for limiting gaming time in Internet cafés) could also be implemented by gaming companies and/or the gaming industry on a selfregulatory basis. For instance, gaming companies could decide to build-in "shutdown" or "fatigue systems" into their games meaning that their game servers could not be reached during the night or a gamer could not play longer than a few hours continuously. Built-in parental controls and warning messages are already available in some games and these could be implemented in many more as part of the companies' or the industry's CSR portfolio. Developing rating systems to evaluate the addictive potential of games could be initiated and carried out by the same self-regulatory associations (having the biggest gaming companies as their members) that created the current rating systems (i.e., ESRB and PEGI) as happens in the lottery industry (where to receive the highest levels of player protection accreditation, the use of game risk tools is almost mandatory (Griffiths, 2012). Finally, increasing the price of specific games or making them less addictive could also be carried out by the gaming companies themselves. However, as already discussed, this seems highly unlikely due to its direct impact on profitability and the gaming operators may feel this is unduly harsh on those gamers who already pay to play. 


\section{DISCUSSION}

This paper provided a systematic review of problematic video gaming policies accompanied by potential ideas from the present authors. The paper attempted to evaluate the efficiency of these policies both theoretically (based on the literature and complemented with the personal opinions of the present authors) and, if data were available, empirically. Overall, it appears that although several steps have been taken to address problematic video game playing, most of these steps were not as effective as expected (Zhan \& Chan, 2012) or had not been evaluated for efficacy. The reason for this may lie in the fact that the policies outlined only address or influence specific aspects of the problem, typically one of the following: (i) gaming time (reducing time spent on gaming), (ii) structural characteristics of the games (changing the addictive potential of games), or (iii) the gamers and their environment (impacting on the psychological and motivational levels).

Reducing time spent on gaming is based on the idea that excessive gaming or increased gaming time is the main source of the problem. Recent research suggests though that this view is deeply misleading. While problematic gamers indeed tend to play much more than healthy gamers, only a minority of excessive gamers experience negative consequences related to their behavior and therefore should not be labeled and treated as problematic gamers (Demetrovics \& Király, 2016; Király, Tóth, Urbán, Demetrovics, \& Maraz, 2017). Case study research has also shown that some gamers can play for very long periods of daily time (over $10 \mathrm{hr}$ a day) with few detrimental effects (Griffiths, 2010). However, controlling time spent on gaming and even more importantly, pursuing, offering, and encouraging other leisure time activities besides gaming may be a useful step in addressing the problem on a large scale.

Changing the structural characteristics and, as a consequence, the addictive potential of games is based on the idea that the way video games are designed are (at least partly) responsible for the development of problematic gaming through the psychological mechanisms that make them immersive and potentially addictive. The acquisition, development, and maintenance of problematic gaming is the result of a complex process and the structural characteristics of games are only a small component in this process (Király, Nagygyörgy, et al., 2014; Kuss \& Griffiths, 2012), and an overemphasis on the structural features could lead to overlooking the importance of player characteristics that warrant targeted prevention measures. However, taking the inherent addictive potential of games into consideration and more importantly, raising awareness of the potential dangers, are most probably useful policy elements.

Finally, trying to help gamers and their families is based on the idea that the development of problematic gaming is mostly related to (or dependent upon) the personal characteristics of gamers [i.e., psychological (e.g., personality), motivational, genetic factors] and their environment, especially their families. Considering that millions of people play online games intensively and only a minority of them show addiction-like symptoms, this approach appears to be the most plausible and has the most support in the literature (see, for instance, Király et al., 2017).

Taking into consideration the complexity of the development of problematic gaming, it is safe to say that targeting the aforementioned aspects separately would most probably have negligible effects - except for the creation and application of good prevention and treatment programs that appear to be effective in themselves (e.g., Lemos, Abreu, \& Sougey, 2014). Moreover, at a policy level, it is assumed that good prevention programs should be prioritized before all other measures because these can address the problem in an early stage and can reach the widest audience thus contributing to a positive outcome (Koo, Wati, Lee, \& Oh, 2011; Turel, Mouttapa, \& Donato, 2015). Nevertheless, creating cohesive and comprehensive regulation by applying multiple policy responses targeting all the aforementioned aspects simultaneously is assumed to be the most efficient.

It is also important to note that general cultural factors and changes need to be taken into consideration when planning policy actions. Given that we now live in an entirely technology-based world, overpathologizing behaviors (Billieux, Schimmenti, Khazaal, Maurage, \& Heeren, 2015) that were unusual a few decades ago but have become parts of normal life today may be more harmful than beneficial for some individuals. Furthermore, a significant difficulty regarding policy measures is that policymakers and those affected generally belong to different generations. More specifically, the majority of current policy measures implemented in Asian countries target minors, while policymakers belong to a generation, which had much less digital technology in their youth and therefore may have a different attitude toward video gaming and Internet use in general. This should be kept in mind and addressed by experts in the field who may be the only ones able to mediate between these two groups. It would also be important to initiate educational campaigns for parents, educators, and policymakers about the real and objective dangers of video game overuse, emphasizing that gaming time alone is not a good indicator of problematic use (Király et al., 2017), and context is much more important when evaluating the risks (Griffiths, 2010).

Finally, there is a cultural aspect to these policies. This review clearly demonstrates that Eastern and Western cultures differ considerably in how they address problematic gaming. Although sharing best policy practices is highly beneficial, due to the significant cultural differences, policy measures should be applied and evaluated locally. For instance, as noted earlier, Eastern cultures tend to view problematic gaming as a public health threat whereas Western countries tend to be far less prescriptive. The reason for this is deeply rooted in cultural aspects. Asian countries place a huge pressure on children and adolescents to perform well in school because of high competition for employment (Lin \& Chen, 1995). Given that excessive gaming is a highly popular leisure activity among youth that can interfere with academic performance, parents and policymakers in these countries view it as a particularly dangerous activity, and therefore, the majority of the policy measures target adolescents in particular. In contrast, academic pressure in the Western world is less oppressive, therefore excessive gaming is less 
feared as a distracting influence. Accordingly, policy actions implemented in the Western world (mostly the treatment programs offered) target all age groups and are much less focused on adolescents compared to those implemented in Asian countries. A further difference is in the therapeutic approach. While in the Western world, disease acceptance is viewed as required for successful treatment in addictions or addiction-like problems, policymakers and parents in Asian countries tend to think that adolescents can be cured even if they do not recognize the problem themselves and/or are resistant to changing their behavior.

It should also be highlighted that this review has some limitations. First, the systematic literature review only focused on academic studies and therefore, other important sources related to policy (e.g., governmental reports) might have been left out. Second, the number of reviewed studies was relatively small, and the majority of the information provided came from non-scientific sources (e.g., newspaper articles cited in academic studies). Third, the majority of the studies concerning policies related to problematic Internet use and gaming exclusively discuss the Korean gaming regulation. Elsewhere, there is a huge gap in the literature regarding such policies internationally. Consequently, this review also included potential policies, regulations, and/or actions. Despite the aforementioned limitations, the review has important strengths. It aimed to systematically examine possible policy responses in the field of problematic video gaming and as such, help all stakeholders in finding powerful solutions together including gamers, friends and family members, treatment providers, prevention experts, game developer companies, and policymakers.

Funding sources: This study was financially supported by the Hungarian National Research, Development and Innovation Office (Grant numbers K111938 and PD121297) and by the Korean Mental Health Technology R\&D Project, Ministry of Health and Welfare, Republic of Korea (HM15C1124). Ágnes Zsila and Orsolya Király were supported by the New National Excellence Program awarded by the Ministry of Human Resources.

Authors' contribution: $\mathrm{OK}, \mathrm{FB}$, and ÁZ reviewed the literature; OK, MDG, DLK, H-KL, S-YL, ZKT, and ZD drafted the manuscript, and all authors agreed on the final manuscript.

Conflicts of interest: The authors do not have any financial or other relations (e.g., directorship, consultancy, or speaker fee) with companies, trade associations, unions, or groups (including civic associations and public interest groups) that may gain or lose financially from the results or conclusions in the study.

Acknowledgements: Sources of funding are gratefully acknowledged. The funding institutions had no role in the study design or the collection, analysis and interpretation of the data, writing the manuscript, or the decision to submit the paper for publication.

\section{REFERENCES}

Aguinis, H. (2011). Organizational responsibility: Doing good and doing well. In S. Zedeck (Ed.), APA handbook of industrial and organizational psychology (Vol. 3, pp. 855-879). Washington, DC: American Psychological Association.

Alexander, L. (2011). Vietnamese gov't puts curfew on online gaming. Retrieved from http://www.gamasutra.com/view/news/ 33143/Vietnamese_Govt_Puts_Curfew_On_Online_Gaming.php (August 22, 2016).

American Psychiatric Association. (2013). Diagnostic and statistical manual of mental disorders (5th ed., text rev.). Washington, DC: American Psychiatric Association.

Auer, M., \& Griffiths, M. D. (2015). Testing normative and selfappraisal feedback in an online slot-machine pop-up message in a real-world setting. Frontiers in Psychology, 6, 339. doi:10.3389/fpsyg.2015.00339

Auer, M., Malischnig, D., \& Griffiths, M. D. (2014). Is 'pop-up' messaging in online slot machine gambling effective? An empirical research note. Journal of Gambling Issues, 29, 1-10. doi:10.4309/jgi.2014.29.3

Azagba, S., \& Sharaf, M. F. (2013). The effect of graphic cigarette warning labels on smoking behavior: Evidence from the Canadian experience. Nicotine and Tobacco Research, 15(3), 708-717. doi:10.1093/ntr/nts 194

BBC News. (2003). Thailand restricts online gamers. Retrieved from http://news.bbc.co.uk/2/hi/asia-pacific/3054590.stm (August 22, 2016). (Archived by WebCite ${ }^{\circledR}$ at http://www.webcitation.org/ 6jx6c33RB)

Bi, M. (2009). Anti-online game addiction system proves to be effective in China. Retrieved from http://news.xinhuanet.com/ english/2009-03/20/content_11044484.htm (August 22, 2016). (Archived by WebCite ${ }^{\circledR}$ at http://www.webcitation.org/ 6jx4WWjVI)

Billieux, J., Schimmenti, A., Khazaal, Y., Maurage, P., \& Heeren, A. (2015). Are we overpathologizing everyday life? A tenable blueprint for behavioral addiction research. Journal of Behavioral Addictions, 4(3), 119-123. doi:10.1556/2006.4.2015.009

Blizzard Entertainment Inc. (2016). Parental controls. Retrieved from https://us.battle.net/account/parental-controls/index.html (August 22, 2016) (Archived by WebCite ${ }^{\circledR}$ at http://www. webcitation.org/6k95CYzk8)

Charlton, J. P., \& Danforth, I. D. W. (2007). Distinguishing addiction and high engagement in the context of online game playing. Computers in Human Behavior, 23(3), 1531-1548. doi:10.1016/j.chb.2005.07.002

China Daily. (2007). The more they play, the more they lose. Retrieved from http://en.people.cn/200704/10/eng20070410 364977.html (August 22, 2016). (Archived by WebCite ${ }^{\circledR}$ at http://www.webcitation.org/6jx1PPNGD)

*Cho, C. M., \& Jin, S. (2015). A policy review on the efforts to prevent Internet addiction in Korea. Journal of Korean Association for Regional Information Society, 18(4), 117-144.

*Chon, C. W. (2009). A study on institutional alternatives for prevention against Internet addiction. Korean Comparative Government Review, 13(2), 303-322. doi:10.18397/kcgr.2009. 13.2.303

Dau, W., Hoffmann, J., \& Banger, M. (2015). Therapeutic interventions in the treatment of problematic Internet useExperiences from Germany Internet addiction. In C. Montag \& 
M. Reuter (Eds.), Internet addiction - Neuroscientific approaches and therapeutical interventions (pp. 183-217). London, UK: Springer.

Davies, B., \& Blake, E. (2016). Evaluating existing strategies to limit video game playing time. IEEE Computer Graphics and Applications, 36(2), 47-57. doi:10.1109/MCG.2016.25

Demetrovics, Z., \& Király, O. (2016). Internet/gaming addiction is more than heavy use over time: Commentary on Baggio and colleagues (2015). Addiction, 111(3), 523-524. doi:10.1111/ add. 13244

Demetrovics, Z., Urbán, R., Nagygyörgy, K., Farkas, J., Griffiths, M. D., Pápay, O., Kökönyei, G., Felvinczi, K., \& Oláh, A. (2012). The development of the Problematic Online Gaming Questionnaire (POGQ). PLoS One, 7(5), e36417. doi:10.1371/ journal.pone.0036417

Dogruel, L., \& Joeckel, S. (2013). Video game rating systems in the US and Europe comparing their outcomes. International Communication Gazette, 75(7), 672-692. doi:10.1177/ 1748048513482539

Eichenbaum, A., Kattner, F., Bradford, D., Gentile, D. A., \& Green, C. S. (2015). Role-playing and real-time strategy games associated with greater probability of Internet Gaming Disorder. Cyberpsychology, Behavior, and Social Networking, 18(8), 480-485. doi:10.1089/cyber.2015.0092

Elliott, L., Golub, A., Ream, G., \& Dunlap, E. (2012). Video game genre as a predictor of problem use. Cyberpsychology, Behavior, and Social Networking, 15(3), 155-161. doi:10.1089/ cyber.2011.0387

Entertainment Software Association. (2015). Facts about the computer and video game industry. Retrieved from http://www. theesa.com/wp-content/uploads/2015/04/ESA-Essential-Facts2015.pdf (July 22, 2017).

Entertainment Software Rating Board. (2016). ESRB ratings guide. Retrieved from https://www.esrb.org/ratings/ratings_ guide.aspx (August 22, 2016).

Game Industry Promotion Act $\S 12.3$. Retrieved from http://www. law.go.kr/lsInfoP.do?1siSeq=188397\&efYd=20170101\#0000 (February 8, 2017).

Geek.com. (2003). Thailand imposes online gaming curfew. Retrieved from http://www.geek.com/games/thailand-imposesonline-gaming-curfew-552405/ (August 22, 2016). (Archived by WebCite ${ }^{\mathbb{B}}$ at http://www.webcitation.org/6jx76mm1j)

Griffiths, M. D. (2010). The role of context in online gaming excess and addiction: Some case study evidence. International Journal of Mental Health and Addiction, 8(1), 119-125. doi:10.1007/s11469-009-9229-x

Griffiths, M. D. (2012). Internet gambling, player protection and social responsibility. In R. Williams, R. Wood, \& J. Parke (Eds.), Routledge handbook of Internet gambling (pp. 227-249). London, UK: Routledge.

Griffiths, M. D., Kuss, D. J., \& King, D. L. (2012). Video game addiction: Past, present and future. Current Psychiatry Reviews, 8(4), 308-318. doi:10.2174/157340012803520414

Griffiths, M. D., van Rooij, A. J., Kardefelt-Winther, D., Starcevic, V., Király, O., Pallesen, S., Müller, K., Dreier, M., Carras, M., Prause, N., King, D. L., Aboujaoude, E., Kuss, D. J., Pontes, H. M., Lopez Fernandez, O., Nagygyorgy, K., Achab, S., Billieux, J., Quandt, T., Carbonell, X., Ferguson, C. J., Hoff, R. A., Derevensky, J., Haagsma, M. C., Delfabbro, P., Coulson, M., Hussain, Z., \& Demetrovics, Z. (2016). Working towards an international consensus on criteria for assessing
Internet Gaming Disorder: A critical commentary on Petry et al. (2014). Addiction, 111(1), 167-175. doi:10.1111/ add. 13057

Hammond, D., Fong, G. T., McDonald, P. W., Brown, K. S., \& Cameron, R. (2004). Graphic Canadian cigarette warning labels and adverse outcomes: Evidence from Canadian smokers. American Journal of Public Health, 94(8), 1442-1445. doi:10.2105/AJPH.94.8.1442

*Han, S. E., \& Koh, Y. S. (2012). A study on the establishment of local governance for the prevention of Internet addiction. The Korea Local Administration Review, 26(3), 461-483.

Huang, X. Q., Li, M. C., \& Tao, R. (2010). Treatment of Internet addiction. Current Psychiatry Reports, 12(5), 462-470. doi:10.1007/s11920-010-0147-1

Huang, X. Q., Zhang, C. H., Li, M., Wang, J., Zhang, Y., \& Tao, R. (2010). Mental health, personality, and parental rearing styles of adolescents with Internet addiction disorder. Cyberpsychology, Behavior, and Social Networking, 13(4), 401-406. doi:10.1089/cyber.2009.0222

Humphreys, K., \& McLellan, A. T. (2011). A policy oriented review of strategies for improving the outcomes of services for substance use disorder patients. Addiction, 106(12), 20582066. doi:10.1111/j.1360-0443.2011.03464.x

Hwang, I. Y., \& Park, J. H. (2015). The impact of government regulations on Korean online game market: A system dynamics approach. Korean System Dynamics Research, 16(4), 129-153.

*Kim, J. K. (2014). A study on dilemma in Internet addiction prevention and solution policy for adolescent. Journal of Digital Convergence, 12(6), 23-34. doi:10.14400/JDC.2014. 12.6.23

Kim, N. R., Hwang, S. S., Choi, J. S., Kim, D. J., Demetrovics, Z., Kiraly, O., Nagygyörgy, K., Griffiths, M. D., Hyun, S. Y., Youn, H. C., \& Choi, S. W. (2016). Characteristics and psychiatric symptoms of Internet gaming disorder among adults using self-reported DSM-5 criteria. Psychiatry Investigation, 13(1), 58-66. doi:10.4306/pi.2016.13.1.58

*Kim, S. T. (2010). A study on the legislative direction for prevention and solution of Internet addiction. Journal of Hongik Law Review, 11(3), 1-39. doi:10.16960/jhlr.11.3. 201010.1

King, D. L., \& Delfabbro, P. H. (2014). Internet Gaming Disorder treatment: A review of definitions of diagnosis and treatment outcome. Journal of Clinical Psychology, 70(10), 942-955. doi:10.1002/jclp. 22097

King, D. L., \& Delfabbro, P. H. (2017). Prevention and policy related to Internet gaming disorder. Current Addiction Reports. Advance online publication. doi:10.1007/s40429-017-0157-8

King, D. L., Delfabbro, P. H., Doh, Y. Y., Wu, A. M. S., Kuss, D. J., Mentzoni, R., Carragher, N., \& Sakuma, H. (2017). Policy and prevention approaches for disordered and hazardous gaming and Internet use: An international perspective. Prevention Science. Advance online publication. doi:10.1007/ s11121-017-0813-1

King, D. L., Delfabbro, P. H., \& Griffiths, M. D. (2010). Video game structural characteristics: A new psychological taxonomy. International Journal of Mental Health and Addiction, 8(1), 90-106. doi:10.1007/s11469-009-9206-4

King, D. L., Delfabbro, P. H., \& Griffiths, M. D. (2011). The role of structural characteristics in problematic video game play: An empirical study. International Journal of Mental Health and Addiction, 9(3), 320-333. doi:10.1007/s11469-010-9289-y 
Király, O., Griffiths, M. D., \& Demetrovics, Z. (2015). Internet gaming disorder and the DSM-5: Conceptualization, debates, and controversies. Current Addiction Reports, 2(3), 254-262. doi:10.1007/s40429-015-0066-7

Király, O., Griffiths, M. D., Urbán, R., Farkas, J., Kökönyei, G., Elekes, Z., Tamás, D., \& Demetrovics, Z. (2014). Problematic Internet use and problematic online gaming are not the same: Findings from a large nationally representative adolescent sample. Cyberpsychology, Behavior, and Social Networking, 17(12), 749-754. doi:10.1089/cyber.2014.0475

Király, O., Nagygyörgy, K., Griffiths, M. D., \& Demetrovics, Z. (2014). Problematic online gaming. In K. Rosenberg \& L. Feder (Eds.), Behavioral addictions: Criteria, evidence and treatment (pp. 61-95). New York, NY: Elsevier.

Király, O., Tóth, D., Urbán, R., Demetrovics, Z., \& Maraz, A. (2017). Intense video gaming is not essentially problematic. Manuscript submitted for publication.

Király, O., Urbán, R., Griffiths, M. D., Ágoston, C., Nagygyörgy, K., Kökönyei, G., \& Demetrovics, Z. (2015). Psychiatric symptoms and problematic online gaming: The mediating effect of gaming motivation. Journal of Medical Internet Research, 17(4), e88. doi:10.2196/jmir.3515

*Koh, Y. S. (2015). The Korean national policy for Internet addiction. In C. Montag \& M. Reuter (Eds.), Internet addiction Neuroscientific approaches and therapeutic interventions (pp. 219-234). London, UK: Springer.

Koo, C., Wati, Y., Lee, C. C., \& Oh, H. Y. (2011). Internet-addicted kids and South Korean government efforts: Boot-camp case. Cyberpsychology, Behavior, and Social Networking, 14(6), 391-394. doi:10.1089/cyber.2009.0331

Korea Creative Content Agency. (2015). White Paper on Korean Games 2015. Seoul, South Korea: Korea Creative Content Agency.

Kuss, D. J., \& Griffiths, M. D. (2012). Internet gaming addiction: A systematic review of empirical research. International Journal of Mental Health and Addiction, 10(2), 278-296. doi:10.1007/ s11469-011-9318-5

Kuss, D. J., \& Lopez-Fernandez, O. (2016). Internet addiction and problematic Internet use: A systematic review of clinical research. World Journal of Psychiatry, 6(1), 143-176. doi:10.5498/wjp.v6.i1.143

Lan, X. Z. (2010). No name, no game. Beijing Review. Retrieved from http://www.bjreview.com.cn/quotes/txt/2010-08/19/ content_292244.htm (August 22, 2016).

Lee, H. K. (2015, November 4). National policy on Internet gaming in Korea. Paper presented at the 12th World Congress of World Association for Psychosocial Rehabilitation (WAPR), Seoul, South Korea.

Lee, H. K., Kim, H. S., \& Lee, T. J. (2011). Cost-effect analysis on the introduction of online game shut down regulation. Seoul, Republic of Korea: Ministry of Gender Equality and Family.

Lee, S.-Y., Lee, H. K., \& Choo, H. (2017). The typology of Internet gaming disorder and its clinical implications. Psychiatry and Clinical Neurosciences, 71, 479-491. doi:10.1111/pcn.12457

Lemos, I. L., Abreu, C. N. D., \& Sougey, E. B. (2014). Internet and video game addictions: A cognitive behavioral approach. Archives of Clinical Psychiatry (São Paulo), 41(3), 82-88. doi:10.1590/0101-60830000000016

Li, J., \& Zhou, V. (2016). Midnight bans and rehab centres on the cards for China's underage gamers. South China Morning Post. Retrieved from http://www.scmp.com/news/china/policies- politics/article/2025821/china-mulls-midnight-ban-childrenplaying-online-games (January 31, 2017).

Lin, J., \& Chen, Q. (1995). Academic pressure and impact on students' development in China. McGill Journal of Education/ Revue des Sciences de l'éducation de McGill, 30(2), 149-168.

Männikkö, N., Billieux, J., \& Kääriäinen, M. (2015). Problematic digital gaming behavior and its relation to the psychological, social and physical health of Finnish adolescents and young adults. Journal of Behavioral Addictions, 4(4), 281-288. doi:10.1556/2006.4.2015.040

Marlatt, G. A. (1996). Harm reduction: Come as you are. Addictive Behaviors, 21(6), 779-788. doi:10.1016/0306-4603(96)00042-1

Ministry of Science - ICT and Future Planning \& National Information Society Agency. (2015). The survey on Internet overdependence. Seoul, South Korea: Ministry of Science, ICT and Future Planning \& National Information Society Agency.

Montag, C., Bey, K., Sha, P., Li, M., Chen, Y. F., Liu, W. Y., Zhu, Y. K., Li, C. B., Markett, S., Keiper, J., \& Reuter, M. (2015). Is it meaningful to distinguish between generalized and specific Internet addiction? Evidence from a cross-cultural study from Germany, Sweden, Taiwan and China. Asia-Pacific Psychiatry, 7, 20-26. doi:10.1111/appy.12122

Müller, K. W., Koch, A., Dickenhorst, U., Beutel, M. E., Duven, E., \& Wölfling, K. (2013). Addressing the question of disorderspecific risk factors of Internet addiction: A comparison of personality traits in patients with addictive behaviors and comorbid Internet addiction. Biomed Research International, 2013, Article ID 546342, 7 pages. doi:10.1155/2013/546342

National Youth Policy Institute. (2013). The survey on youth media usage. Seoul, South Korea: National Youth Policy Institute.

OECD. (2016). Households with broadband access. Retrieved from http://www.oecd-ilibrary.org/science-and-technology/households-with-broadband-access/indicator/english_f9b84af5-en (August 22, 2016).

*Park, B. W., \& Ahn, J. H. (2010). Policy analysis for online game addiction problems. System Dynamics Review, 26(2), 117-138. doi: $10.1002 / \mathrm{sdr} .436$

Park, J.-E. (2012). Comparative study: Restriction on video game to minors in the US and its unconstitutionality, its estimation and suggestion. Lawyers Association Journal, 61(8), 223-273. doi:10.17007/klaj.2012.61.8.006

Park, M. S., Ko, T. Y., \& Park, J. S. (2013). Impacts and implications of game market regulation on the development of industrial ecological system. Seoul, South Korea: Korea Institute for Industrial Economics and Trade (KIET). Retrieved from http:/ www.kiet.re.kr/kiet_web/index.jsp?sub_num $=8 \&$ state= $=$ view $\&$ tab $=$ list $\& \mathrm{idx}=45423 \&$ sty $=\mathrm{W} \& \mathrm{ste}=\% \mathrm{EA} \% \mathrm{~B} 2 \% 8 \mathrm{C} \% \mathrm{EC} \% 9 \mathrm{E} \%$ 84\&ord=10 (July 22, 2017).

Peren, F. W. (2011). Assessment tool to measure and evaluate the risk potential of gambling products: Asterig. Journal of Gambling Business and Economics, 5, 54-66. doi:10.1089/ glre.2011.151107

Pontes, H. M., Macur, M., \& Griffiths, M. D. (2016). Internet gaming disorder among Slovenian primary schoolchildren: Findings from a nationally representative sample of adolescents. Journal of Behavioral Addictions, 5(2), 304-310. doi:10.1556/2006.5.2016.042

Prabhu, T. (2014). ReThink Before You Type - Trisha Prabhu [Video file]. Retrieved from http://tedxteen.com/talks/ tedxteen-2014-london/258-trisha-prabhu-rethink-before-youtype (August 22, 2016). 
Rawes, E. (2016). 10 of the most addictive video games ever made. Retrieved from http://www.cheatsheet.com/technology/10of-the-most-addictive-video-games-ever-made.html/?a=viewall (August 22, 2016).

Rehbein, F., \& Mößle, T. (2013). Video game and Internet addiction: Is there a need for differentiation? SUCHT, 59(3), 129-142. doi:10.1024/0939-5911.a000245

Scharkow, M., Festl, R., \& Quandt, T. (2014). Longitudinal patterns of problematic computer game use among adolescents and adults - A 2 year panel study. Addiction, 109(11), 19101917. doi:10.1111/add.12662

Seo, J. (2017). China increasing Internet game regulation by introducing game shutdown system; enewstoday.co.kr. Retrieved from http://www.enewstoday.co.kr/news/articleView.html?idxno= 675510 (January 31, 2017).

*Shin, J. H., \& Chae, S. E. (2015). A needs analysis for teacher training programs and policies to solve adolescents' Internet, game, and media addiction. Korean Journal of Teacher Education, 31(3), 357-378. doi:10.14333/KJTE.2015.31.3.357

Statistics Korea. (2016). The Internet usage rate within last 1 month. Retrieved from http://www.index.go.kr/potal/govindic/userPage Ch.do?idx_cd=2954 (July 22, 2017).

*Stone, R. (2009). China reins in wilder impulses in treatment of 'Internet addiction'. Science, 324(5935), 1630-1631. doi:10.1126/science.324_1630

Sung, W. (2014). A study on the effect of the policy of online game shutdown on the game time of youth. Social Science Research Review, 30(2), 233-256.

Tessényi, J., \& Peren, F. W. (2015). ASTERIG. A szerencsejátéktermékek függ ségi kockázatainak egy lehetséges mérése és empirikus vizsgálata a Magyarországon kínált szerencsejátékokra. Alkalmazott Pszichológia, 15(4), 47-56. doi:10.17627/ ALKPSZICH.2015.4.47

thel.mt.co.kr. (2016). Disclosing the data for 'items of chances' .... a regulation or consumer protection? Retrieved from http://thel. $\mathrm{mt} . \mathrm{co} \cdot \mathrm{kr} / \mathrm{newsView} \cdot \mathrm{html}$ ?no=2016030313358240325 (October 16, 2016).

thisisgame.com. (2015). How items of chances are regulated in overseas? Retrieved from http://www.thisisgame.com/webzine/ news/nboard/11/?n=58449 (October 16, 2016).
Thorens, G., Achab, S., Billieux, J., Khazaal, Y., Khan, R., Pivin, E., Gupta, V., \& Zullino, D. (2014). Characteristics and treatment response of self-identified problematic Internet users in a behavioral addiction outpatient clinic. Journal of Behavioral Addictions, 3(1), 78-81. doi:10.1556/JBA.3. 2014.008

Turel, O., Mouttapa, M., \& Donato, E. (2015). Preventing problematic Internet use through video-based interventions: A theoretical model and empirical test. Behaviour \& Information Technology, 34(4), 349-362. doi:10.1080/0144929X.2014. 936041

*van Rooij, A. J., Meerkerk, G., Schoenmakers, T. M., Griffiths, M. D., \& van de Mheen, D. (2010). Video game addiction and social responsibility. Addiction Research \& Theory, 18(5), 489-493. doi:10.3109/16066350903168579

Wölfling, K., Beutel, M., Dreier, M., \& Müller, K. (2014). Treatment outcomes in patients with Internet addiction: A clinical pilot study on the effects of a cognitive-behavioral therapy program. Biomed Research International, 2014, Article ID 425924. doi:10.1155/2014/425924

World Health Organization. (2014, 27-29 August). Public health implications of excessive use of the Internet, computers, smartphones and similar electronic devices - Meeting report, Main Meeting Hall, National Cancer Research Centre, Tokyo, Japan. Geneva, Switzerland: World Health Organization.

YonhapNews. (2015). S. Korea has 4th highest smartphone penetration: Data. Retrieved from http://english.yonhapnews.co.kr/ business/2015/07/08/91/0503000000AEN20150708000700 320F.html (October 5, 2016).

*Yousafzai, S., Hussain, Z., \& Griffiths, M. (2014). Social responsibility in online videogaming: What should the videogame industry do? Addiction Research \& Theory, 22(3), 181-185. doi: $10.3109 / 16066359.2013 .812203$

*Zhan, J. D., \& Chan, H. C. (2012). Government regulation of online game addiction. Communications of the Association for Information Systems, 30, Article ID 13. Retrieved from http:// aisel.aisnet.org/cais/vol30/iss1/13 